\title{
OLHARES HISTORICAMENTE CONSTRUÍDOS SOBRE A PLANÍCIE PANTANEIRA*
}

\author{
HISTORICAL LOOKS ON PANTANAL PLAIN
}

Miradas históricamente construida sobre las LlanURAS del PANTANAL.

\author{
Ilsyane do Rocio Kmitta** \\ ilsyanekmitta2@ibest.com.br \\ Débora Fernandes Calheiros ${ }^{* * *}$ \\ debora@cpap.embrapa.br
}

RESUMO: O presente artigo está associado ao projeto de pesquisa, cujo objetivo geral é analisar as transformações ambientais no Pantanal de Corumbá/MS no período que compreende os anos de 1950-1990. A proposta de trabalho está vinculada ao campo de pesquisa da História Ambiental que permite fazer uma breve análise do processo de transformações no Pantanal e como tais mudanças alteraram ao longo do tempo a relação do homem com a natureza na planície pantaneira. A ideia inicial

* Discussões iniciais apresentadas no texto, salvo modificações e sem coautoria, foi publicado nos Anais do XXVI Simpósio Nacional da ANPUH/USP - 2011, com o título "Notas sobre as transformações ambientais na planície pantaneira". Para auxiliar na leitura, salientamos que o Pantanal, classificado como a maior área alagável conhecida, localiza-se na Bacia do Alto Paraguai, na porção Centro-Sul do Continente Sul Americano. Abrangendo os Estados de Mato Grosso e Mato Grosso do Sul. Com uma extensão de $140.000 \mathrm{Km}^{2}$. Integrando o conjunto de áreas úmidas mundiais, situadas geograficamente em vários pontos do planeta. Face aos estereótipos construídos historicamente e socialmente em relação ao Pantanal, o mesmo foi declarado Patrimônio Nacional pela Constituição Brasileira de 1988. Em 2000, foi considerado pela Organização das Nações Unidas pela Educação, Ciência e Cultura (UNESCO) como uma região intocada. Prioritariamente para a conservação ambiental que se interliga a um sistema maior de áreas úmidas da grande Depressão da América do Sul. Ante essa designação, atribui-se aos Pantanais o "status" de patrimônio da humanidade.

Para estudos sobre a origem histórica do termo Pantanal sugerimos a leitura de: COSTA. $\mathrm{M}^{\mathrm{a}}$ de F. História de um país inexistente: o Pantanal entre os séculos XVI e XVIII. São Paulo: Estação Liberdade/ Kosmos, 1999; e NOGUEIRA, Albana Xavier. O que é Pantanal. São Paulo: Brasiliense, 1990.

** Doutoranda/pesquisadora. Programa de Pós-graduação da Universidade Federal da Grande Dourados $\mathrm{PPGH} / \mathrm{UFGD}$.

*** Doutora em Ciências, pelo Centro de Energia Nuclear na Agricultura, da Universidade de São Paulo (CENA/USP) e pesquisadora da Embrapa Pantanal

Ilsyane do Rocio Kmitta | Débora Fernandes Calheiros OLHARES HISTORICAMENTE CONSTRUÍDOS SOBRE A PLANÍCIE PANTANEIRA 
parte de uma reflexão de que as ações não são isoladas e conhecer historicamente tais transformações permite a compreensão de que as modificações, muitas delas provocadas pela implantação de programas de desenvolvimento, provocaram sérios danos aos ecossistemas, afetando o ciclo das águas que são característica inerente dos pantanais. Analisamos que os impactos gerados por essas transformações foram sentidos não apenas na economia como também no meio ambiente e na cultura, desnudando assim, a vulnerabilidade dos pantanais.

PALAVRAS-ChAVE: Pantanal; natureza; desenvolvimento.

ABSTRACT: This paper is associated with the research project whose general goal is to analyze the environmental changes in the Pantanal Corumbá/MS in the years 1950-1990. The proposed work is linked to the search field of Environmental History allowing a brief analysis of the process of change in the Pantanal and how these changes have altered over time man's relationship with nature. The first idea is that the actions are not isolated and knowing historically such transformations allow the understanding that the amendments, many of them by the implementation of development programs, caused serious damage to ecosystems, affecting the water cycle that is an inherent characteristic of Pantanal. We analyze the impact generated by these transformations were not felt only in the economy, but also the environment and culture, thus showing Pantanal's vulnerability.

KEYWORDS: Pantanal; nature; development.

RESUMEN: Este artículo está relacionado con el proyecto de investigación cuyo objetivo general es analizar los cambios ambientales en el Pantanal Corumbá / MS en el período que comprende los años 1950 a 1990. El trabajo propuesto está relacionado con el campo de búsqueda de la historia ambiental permitiendo un breve análisis de los procesos de cambio en el Pantanal y cómo estos cambios han alterado a lo largo del tiempo la relación del hombre con la naturaleza en las llanuras de inundación. La idea inicial parte de una reflexión que las acciones no están aisladas y conocer históricamente tales transformaciones permite el entendimiento de que las 
enmiendas, muchas de ellas causadas por la aplicación de programas de desarrollo, causaron graves daños a los ecosistemas, afectando el ciclo del agua, que es una característica inherente de los humedales. Analizamos que los impactos generados por estos cambios fueron sentidos no solamente en la economía, sino que también en el medio ambiente y en la cultura, mostrando así la vulnerabilidad de los humedales. Palabras clave: Pantanal, la naturaleza, el desarrollo.

"O silêncio implica na cumplicidade na construção do esquecimento."4

As mudanças pelas quais a História tem passado aliada à abertura do diálogo entre as Ciências Humanas incidem no surgimento de abordagens e paradigmas que, somados às diversas áreas do conhecimento, permitem analisar e discutir temáticas cada vez mais instigantes no campo da História. As perspectivas de novos quadros de pesquisas lançam o historiador na trilha de questões epistemológicas que englobam diversos objetos e as mais variadas fontes que resultam na escrita de textos ricos em questionamentos, possibilitando, em parte, algumas respostas para as indagações/interrogações pertinentes à historiografia que incluem a análise do processo histórico, a forma como é elaborado esse processo na História e como foi e/ou é construído historicamente.

Nesse contexto, ao escrever sobre as bases teóricas da História Ambiental, Pádua (2010) salienta que enquanto campo historiográfico, a História Ambiental estrutura-se a partir da década de 1970. Desde então até à atualidade, as questões ambientais em discussão estão imbricadas com a globalização, integrando assim, as agendas políticas, econômicas e culturais. E mais, para o autor,

A História Ambiental emergente no Século XX, no entanto, é bem mais complexa do que um inventário diacrônico dos males infringidos pelos seres humanos ao planeta. Ela incorpora outras transformações 
teóricas que merecem ser discutidas com destaque [...] (PÁDUA, 2010, p. 86).

É possível, produzir diálogos profícuos no campo da História Ambiental, com o conhecimento historicamente construído que contemplem em seus objetos as formações sociais, culturais, econômicas e políticas e como, no conjunto, favoreceram determinados acontecimentos. Recorremos a Martinez quando o autor salienta que:

História Ambiental é antes de tudo História. $O$ desafio é permanecer na condição de historiador, ou seja, seguir nas análises e reflexões dentro dos padrões historiográficos que requer a construção de conhecimentos históricos contemporâneos (MARTINEZ, 2006, p.30).

Para Leff (2005), as discussões que emergem no que tange ao meio ambiente não podem ser dissociadas dos discursos políticos e científicos de nosso tempo. São análises que demonstram a concepção de mundo, de desenvolvimento e das relações da sociedade e, dela para com a natureza. É um campo de saber que vem completar as indagações propostas pelo processo acelerado de modernidade e dos variados campos de conhecimento. $E$, dentre as disciplinas científicas e de formação profissional, a História é um campo vasto de análise e elaboração de conhecimento científico com metodologias que possibilitam questionamentos sobre as estruturas, as ações humanas e suas formas de se relacionar com a natureza ao longo do tempo. A História Ambiental propicia indagações sobre as temporalidades, identidades, processos culturais, políticos e econômicos, tecnologias e abordagens sobre o meio ambiente como um campo de relações do homem com a natureza.

$\mathrm{Na}$ análise de Leff, os estudos desenvolvidos pela História Ambiental envolvem os diferentes modos de produção, das formações sociais, dos impactos e transformações ambientais. Abordam a análise de padrões de uso dos recursos e formas de apropriação da natureza seguindo por categorias que permitem o estudo das interrelações entre as estruturas 
econômicas, políticas e culturais que induzem e/ou geram certos padrões de uso dos recursos e das condições ambientais que, por sua vez, estabelecem condições de sustentabilidade ou não de um determinado território. (2005, p. 17)

Partindo dessa premissa, apresentamos uma análise sobre as modificações e/ou transformações ambientais pelas quais o Pantanal vem passando, de forma mais intensa desde meados do Século XX, expondo os ecossistemas da planície pantaneira as mais graves ameaças, dentre elas, o desmatamento e o assoreamento dos rios, aspectos que interferem significativamente na vazão do chamado ciclo das águas.

Nos anos de 1940, em 1947 mais especificamente, ocorre um processo mais intenso de colonização no Norte de Mato Grosso, no planalto, com a implantação de projetos oficiais e de empresas particulares e estrangeiras gerando um promissor mercado de aquisição e exploração de terras e da extração de madeira, facilmente comercializadas. O destaque para a comercialização de madeira está presente em "Corumbá: Reminiscências e Impressões", quando o autor lamenta a caça indiscriminada, a devastação e as queimadas, a implantação de fazendas e o aumento da população rural, que atuavam como fator relevante para a alteração e desequilíbrio ecológico no Pantanal de Corumbá (BAEZ, 1975).

Nos anos de 1960, novos olhares são lançados sobre a região da bacia hidrográfica do Alto Paraguai que compreende o Pantanal MatoGrossense ou os diferentes pantanais ${ }^{5}$. Constatamos que o Diário Oficial nos anos de 1964 e 1965 apresenta inúmeros editais de compra e venda de terras devolutas, de medição e retificação de limites, de remarcação de lotes, de aprovações de demarcações, de concessão de venda, realizados através da Delegacia Especial de Terras e Colonização. Uma parcela considerável dessas terras era/foi destinada para a criação de bovinos. Na análise de Corrêa (1990, p. 96), nos pantanais, em função de seu ambiente típico modelado por 
um complexo regime de cheias e vazantes, surgiria um modelo de economia peculiar, onde a atividade da criação de bovinos seria um fator viabilizador do desenvolvimento e do uso do solo pantaneiro.

A perspectiva da ocupação de áreas como o Pantanal, suscitava a adoção e organização de mecanismos facilitadores, no que tange as comunicações e ao transporte, amenizando e facilitando o rompimento das longas distâncias, bem como amenizando os prejuízos das grandes inundações, da precariedade do acesso às fazendas e do isolamento geográfico em relação aos demais centros econômicos do país. Era preciso fixar núcleos urbanos, estabelecer e estruturar núcleos políticos instaurando um processo amplo e dinâmico na economia para o Mato Grosso. ${ }^{6}$

Uma política desenvolvimentista estimulou a ocupação das terras, com deslocamentos que estabeleceram novas formas de ocupação social e espacial no centro-oeste do Brasil. Silva (2010, p. 320) analisa que o Brasil "através da ditadura militar forjou as condições política e sociais para o implemento de um novo modelo capitalista assentado no capital estrangeiro". Com isso, instaurou um novo processo de ocupação de terras para manter-se no novo contexto econômico baseado na agricultura que aliada ao setor industrial vai imprimir um "novo padrão produtivo baseado no cultivo intensivo do solo, na utilização de insumos químicos e no emprego de máquinas industrializadas" (BRUM, 1988 apud SILVA, 2010, p. 320). O processo intenso de ocupação de terras no planalto inicia uma acelerada ação antrópica desvendando os diferentes espaços, expressões simbólicas e culturais dos pantanais.

O Estado incentiva a política agrícola assegurando através de créditos e da ação de órgãos ligados ao governo o processo de modernização alterando o padrão produtivo agrícola e da pecuária, embora nenhuma alteração tenha sido efetuada na estrutura agrária e aquisição de terras. Na análise de Silva (2010), registros apontam que é entre os anos de 1970 e 
1980 que ocorreu um significativo acréscimo na utilização de maquinários nas lavouras, e nas regiões Sul e Centro-Oeste, esse montante é superior às demais regiões do país. É também a região Centro-Oeste, segundo o autor, que registra um maior crescimento para o período recebendo maiores incrementos "em virtude da expansão da soja e da pecuária sobre essa região" (SILVA, 2010, p. 323).

Em agosto de 1965, o Diário Oficial apresenta o relatório anual da Companhia Agrícola de Mato Grosso, datado de 30 de dezembro de 1964. A descrição feita impressiona pela forma como é apresentado o desenvolvimento do Estado vinculado às ações da referida companhia. Aos olhares empreendedores o Estado desfrutava de um "surto violento de progresso" constando as ocupações de suas terras "virgens e inexploradas" e a avidez na exploração de suas reservas. Ao mesmo tempo em que enaltece o avanço no processo de desenvolvimento, incentivando a abertura de novas áreas para o cultivo e pecuária, a inserção de novas tecnologias para melhoria e aumento da produção, chama a atenção para a necessidade do cuidado no avanço de algumas áreas, salientando que era preciso o "aproveitamento racional das nossas terras e da proteção de nossas matas" com o cuidado de não deixar um rastro de destruição ambiental como verificado em outros Estados cujas "reservas florestais foram destruídas prejudicando as fontes d'água e aniquilando sua fauna e sua flora".

Segundo Vargas (2006), foi após a década de 1960 que o Pantanal passa a ser reconhecido como uma região rica em sua biodiversidade, e muitas práticas ali adotadas para o desenvolvimento de atividades econômicas, passam a ser questionadas. Tal questionamento está atrelado ao fato de que a década de 1960 apresenta a degradação ambiental como um sério problema, seja em âmbito social, político, ecológico e econômico. Despontam debates no cenário internacional, enfatizando a necessidade de políticas preservacionistas. A Conferência das Nações Unidas da Biosfera, 
em 1968, reuniu especialistas discutindo os problemas ambientais de forma global, resultando na percepção dos efeitos negativos oriundos de um processo exploratório da natureza. A constatação dos crescentes efeitos da degradação ambiental foi foco de debates nas décadas de 1960-1970 (KMITTA, 2010, p. 191).

Com a introdução de muitos elementos alheios ao ambiente pantaneiro e as novas práticas culturais e sociais nocivas, de acordo com $A b$ 'Saber (2006, p. 14), exigem "um novo padrão de entendimento" porque estão concatenadas com um projeto desenvolvimentista que protagoniza severas transformações em um ambiente com ecossistemas singulares, visto que "trata-se, assim, de uma célula espacial do país que está a exigir uma extensão administrativa particularizada, e um novo padrão de controle, por parte do Estado e da sociedade brasileira" (op. cit.).

Ao analisar a atividade dos peões na condução das comitivas e a relação do homem com o meio ambiente nos pantanais, bem como o processo de modificações de tais atividades, Leite (2005) apresenta que parte da base estruturante dessa relação entre homem e natureza está relacionada às características ambientais próprias da planície. Em sua análise, o autor avalia que a ocupação econômica da região e o desenvolvimento das mais variadas atividades sempre tiveram como marco balizador "a presença da natureza e de suas particularidades especialmente as grandes enchentes e sua antítese, as secas" (LEITE, 2005, p. 174). A depressão pantaneira é tomada durante a estação chuvosa por inundações que têm um impacto profundo sobre a relação do ser humano com o local, por conta de sua ação de renovação das gramíneas e outras espécies da flora nativa de grande importância para a expansão da atividade pecuária (WILCOX, 2001, p. 121).

Nesse contexto, Proença (1992) apresenta ideia semelhante em "Pantanal: gente, tradição e História" quando escreve:

No Pantanal tudo depende das águas. São elas que condicionam os diversos tipos de vida, levam o homem a ter necessidade de mudanças Hist. R., Goiânia, v. 19, n. 2, 2014 
nas grandes enchentes, modificam os solos, obrigam certas aves a migrar para outros lugares do planeta, empurrando o gado para cima das cordilheiras, quebram a monotonia da planície, ilhando muitas fazendas, obrigando ao emprego de canoas que substituem os cavalos para conduzir a criação aos lugares mais altos e, portanto, livres do desespero das águas (PROENÇA, 1992, p. 13).

A singularidade da natureza está associada à própria nominação Pantanal, que, segundo alguns autores, abrangem em seu interior diferentes pantanais ou sub-regiões de acordo com o tipo de solo, vegetação ou nível de inundação (HAMILTON; SIPPEL; MELACK, 1996; SILVA \& ABDON, 1998). Isso posto se considerarmos que o Pantanal é apresentado como um patrimônio, um espetáculo da natureza, uma paisagem exuberante pela mídia, para os habitantes da planície pantaneira, o mesmo é o seu lócus e "é visto e sentido a partir de uma perspectiva utilitária, e também como o meio social, o mundo vivido" (VARGAS, 2006, p. 1). Portanto, em conformidade com a autora há uma duplicidade de sentidos que compreende o ver e sentir.

A relação do homem com a natureza suscita diferentes níveis de percepções advindas das experiências do vivido. Recorrendo a Tuan (1980, p. 5), podemos utilizar, nessa perspectiva, a expressão topofilia que, de acordo com o autor, "é o elo afetivo entre a pessoa e o lugar ou ambiente físico". A água exerce uma função simbólica extremamente eloquente quanto se trata dos pantanais. Sua ambiguidade enquanto portadora da vida e da morte pode ser associada a sua imensidão e capacidade de regeneração. Retornamos a leitura de Yi-Fu Tuan (1980, p. 26), onde o autor analisa que "um símbolo é uma parte, que tem poder de sugerir um todo", onde muito dos significados são orientados culturalmente. É relevante destacar aqui, que em basicamente toda a escrita memorialística sobre o Pantanal, encontramos elementos que compõem o universo cultural pantaneiro em que a água integra a construção de uma visão de mundo e consequentemente das representações e das apropriações. 
Surgem interesses convergentes do Estado e dos proprietários de terras, primordialmente nas áreas de planalto que circundam a planície, ou seja, do empresariado rural, frente às possibilidades que se apresentavam para novos investimentos. Recursos oriundos de programas e fundos de fomento do Governo Federal, criados a partir da década de 1960, visando modernizar setores como da agropecuária e a agroindústria no Brasil. Investimentos destinados à limpeza dos campos, formação e melhoria das pastagens, aquisição de maquinários e equipamentos, construção de benfeitorias, propiciando um melhor retorno na produção e acelerando o desenvolvimento da região, aproveitando o potencial econômico em áreas especificas do centro-oeste, leia-se Pantanal. Em 1967, a criação da Superintendência de Desenvolvimento do Centro-Oeste (SUDECO) é parte das reformas estratégicas do Governo Federal para o Pantanal.

A década de 1970 chega trazendo promessas milagrosas de desenvolvimento. No período de 1974-1976 o Programa de Desenvolvimento do Pantanal (PRODEPAN) ${ }^{7}$, sob a coordenação da SUDECO, criava um polo de desenvolvimento no Pantanal do Mato Grosso, cujos empreendimentos trouxeram para a região impactos que foram sentidos não apenas na economia ${ }^{8}$ como também no meio ambiente ${ }^{9}$. Proença (1997) assim registra tal fato:

A ideia era de implantar um sistema de malhas viárias, saneamento ambiental, energia, desenvolvimento da pecuária de corte, industrialização. Porém, o que se viu foram projetos executados pela metade como a Transpantaneira e outros que nem saíram das gavetas, ou se transformaram em secundários em vista das inúmeras outras obras, que se realizavam no país naquela época dourada (PROENÇA, 1997, p. 152).

Em 1974, na sessão de abertura do I Encontro do PRODEPAN, o discurso do então Governador do Estado ressaltava que tudo que é novo precisa ter um símbolo, que por sua vez, represente uma aventura e, foi lançada a Transpantaneira. Um símbolo, um ponto de referência, uma aventura que Hist. R., Goiânia, v. 19, n. 2, 2014 
surgiu como um desafio para o povo e para as autoridades. Símbolo que motivou a opinião pública em âmbito nacional, uma mobilização nacional "em torno do problema agudo e promissor no Pantanal". Uma intervenção monstruosa, que partiu da ideia do governo de interligar Poconé, no extremo norte do Pantanal, a Corumbá, no extremo sul. A Transpantaneira, símbolo do PRODEPAN, começa em Poconé, como previsto, mas termina abruptamente nas margens do rio Cuiabá com $147 \mathrm{~km}$ e 126 pontes - considerado por muitos como um recorde mundial.

Outros programas de estratégias de desenvolvimento para a região foram também criados como o Estudo de Desenvolvimento Integrado da Bacia do Alto Paraguai (EDIBAP) /Brasil (1979), o Plano de Conservação da Bacia do Alto Paraguai (Pantanal) (PCBAP) /Brasil (1997) e o Programa Pantanal (BRASIL, 2001), todos recomendando o uso dos recursos naturais de forma mais racional, visando à sustentabilidade. Mas na prática bem pouco ou quase nada do que foi proposto nestes estudos foi realmente aplicado. De fato, apenas o modelo econômico tradicional vigora e se impõe. O PCBAP se destaca por ser um projeto ambicioso, elaborado tendo como base o EDIBAP, cujas finalidades estavam centradas em aspectos como o apontamento dos principais problemas no desenvolvimento das atividades econômicas na planície e os possíveis danos ambientais causados. Seu foco estava voltado para a agropecuária, extração de minerais, implantação de indústrias.

Descobrir a vulnerabilidade dos pantanais foi o passo seguinte do processo de desenvolvimento. A substituição da vegetação nativa por áreas de pastagens e da agricultura, em especial na área de planalto dentro de uma exploração imediatista, e "modernizadora", gerou consequências não apenas de curto, bem como as que afloraram em longo prazo nos pantanais. Leite (2003) faz uma análise de tais transformações. Para o autor, essas mudanças estão atreladas a exigências de um mercado consumidor cada vez mais seletivo e restrito que interfere grandemente na organização das 
fazendas. Assim, para atender tais expectativas "estradas são bloqueadas, novas divisões internas são operadas, áreas são vendidas, mas, sobretudo, costumes, hábitos e formas de tratamento são modificadas ainda que lentamente, quase imperceptíveis" (LEITE, 2003, p. 133).

A venda e fragmentação de muitas propriedades, após a enchente de 1974, desencadearam um processo acelerado de novos investimentos de agropecuárias que tem no gerenciamento a condução dos negócios e com isso o proprietário vindo de fora fica ausente da propriedade e tem muito pouca identidade com o lugar, com suas especificidades e singularidades. As relações entre patrão e empregado ganham, pois, novos contornos. Campos (2004) analisa tais mudanças e cita parte de uma entrevista:

Patrão trabalhava rente com os peões. Não tinha esse negócio só de mandar, eles sabiam fazer. Pra saber mandar, tem que saber fazer, né. Clareava rente com a peonada. O respeito nas relações de trabalho, sobretudo no campo, baseava-se nesse compartilhar as agruras e durezas do cotidiano, lado a lado (CAMPOS, 2004, p. 105).

A partir desse fragmento de entrevista, é possível perceber que se inicialmente a relação de trabalho estava pautada na confiança e no respeito, fatores que geravam uma horizontalidade nessa relação que incluía moradia para as famílias, alimentação e convívio permanente entre proprietários e empregados que cotidianamente compartilhavam suas experiências na busca de maior eficiência e melhores resultados na produção, agora resulta em uma relação estritamente funcional, inibindo uma maior aproximação e o descrédito. Acrescente-se, nesse contexto de mudanças, a aplicação das leis trabalhistas que passaram a regular e contabilizar as horas trabalhadas.

Consequentemente, a relação do homem com a natureza, com o meio ambiente pantaneiro sofre alterações em função da inserção de novos métodos de trabalho onde ora a natureza atua como aliada, ora como empecilho. Paisagens que outrora foram descritas por viajantes, contidas nas representações cartográficas que expressavam percepções e sensibilidades, 
imagens essas que tanto quanto encantavam, desesperavam e colocavam à prova a persistência e a determinação de "domar a natureza", passaram ao longo dos anos por transformações, muitas vezes, imperceptíveis. No entanto, são portadoras de novas representações, de identidades, de um texto que pode apresentar inúmeras contradições.

No passado, a pecuária extensiva tradicional na região pantaneira realizada desde os primeiros colonizadores era feita sem muitas intervenções na paisagem ou no funcionamento ecológico do sistema. O pantaneiro, seja ele dono de grandes ou pequenas propriedades, convivia de modo mais natural, conhecia o ritmo das águas, as características e dificuldades inerentes ao ambiente, dele retirando seu sustento e seu lucro, nele embasando sua cultura, sua história e seu lazer. ${ }^{10}$ Contudo, com a chegada dos novos investidores, oriundos de outros Estados e com a "mudança de mãos" nas propriedades, a habitual relação intrínseca com a terra e a água se perdeu. $A$ avidez pelo lucro e por melhores rendimentos chegou trazendo a aceleração dos processos de desmatamento, uniformização e maximização do lucro, aplicando literalmente o "modus operandi" insustentável social e ambientalmente em seus estados de origem.

As constantes mudanças e transformações operadas nos pantanais como consequência do mau uso dos recursos naturais no planalto e, a partir de meados da década de 1990 , com avanço do desmatamento na própria planície pantaneira estão ligadas com fatores como a "modernização" das práticas agrícolas, a globalização do mercado e a busca por eficiência econômica máxima, em detrimento da conservação do ambiente que Ihes provê, que thes oferece o que é agora denominado como serviços ambientais. Tal avanço desencadeou sérios problemas sócio-ambientais frente ao avanço agroindustrial propagado pelo Governo vislumbrando uma revolução agrícola no centro oeste do Brasil, o mesmo modelo econômico implantado na década de 1960 se mantém até hoje, com base na exploração 
agressiva dos recursos naturais, com privatização dos lucros e socialização das perdas, contaminação dos recursos hídricos, perdas de solo, assoreamento de rios, perda de biodiversidade, perda de qualidade ambiental e de vida para as comunidades que dependem da saúde ambiental dos pantanais, como ribeirinhos, comunidades tradicionais, pescadores, setor de turismo e navegação, além da própria pecuária pantaneira.

A ideia de uma política desenvolvimentista, da era militar, incluía projetos agropecuários formatando um processo de "nova colonização". Paralelo a esse fato, a Secretaria do Meio Ambiente do Ministério do Interior (SEMA) viabilizava a criação de estações ecológicas nos principais ecossistemas que incluíam a Amazônia, Floresta de Araucárias, Pantanal, Mangues do Amapá, Serra do Tabuleiro entre outras, totalizando doze estações. $\mathrm{O}$ objetivo científico era instalar laboratórios destinados ao estudo comparativo dos recursos naturais no território brasileiro.

Discurso semelhante ao propalado pelo governo, através da SEMA, pode ser encontrado no prefácio e apresentação da obra intitulada "Pantanais Matogrossenses" (Devassa e Ocupação), de Virgílio Correa Filho, escrito em 1946, atendendo ao pedido da Biblioteca Geográfica Brasileira e publicado pelo Instituto Brasileiro de Geografia e Estatística (IBGE). Obra essa, considerada pelo Instituto, como uma importante contribuição na constituição da geografia regional do Brasil. Assunto que vinha aos poucos atraindo estudiosos para a necessidade de analisar regiões distintas, isoladas em suas características para depois buscar uma aproximação de forma a englobar no conjunto geral.

Retomando a discussão quanto ao papel da SEMA nos primórdios da gestão de meio ambiente no país, podemos considerar que essa pode ser considerada a primeira tentativa em termos práticos de executar políticas de proteção ao meio ambiente e a preservação de recursos naturais. A própria criação da SEMA foi o resultado da participação do Brasil na Conferência 
da ONU, em Estocolmo, em 1972. Entre as atribuições do SEMA constava a elaboração, controle e fiscalização das normas e padrões relativos à preservação do meio ambiente e a cooperação na preservação de espécies animais e vegetais ameaçados de extinção. Pesca predatória, caça de animais em extinção, assoreamento e contaminação dos rios, matança de jacarés, a substituição da floresta nativa pela soja nas fronteiras agrícolas, tudo isso eram demandas da época que, no entanto, continuam sendo ameaças constantes nos pantanais.

Nessa perspectiva, é possível observar que no Pantanal MatoGrossense as diferentes utilizações do espaço e os modos de se relacionar com a natureza e a sua utilização estão diretamente ligados às atividades econômicas desenvolvidas, gerando conflitos no que tange à manutenção da produção e da conservação ambiental, dos interesses e formas de vida dos grupos locais, que contrastam com a dos novos proprietários. A relação do homem com a natureza passou por variações, as quais podem ser percebidas nas narrativas encontradas em trabalhos como os de Nogueira (2002); Fernandes (2002); Leite (2003); Banducci Júnior (2007), entre outros. Tais trabalhos permitem uma análise dos processos de mudanças na relação do homem com a natureza e como a tradição oral continua muito forte, sobretudo nas memórias e/ou lembranças das pessoas mais velhas.

Verifica-se também que a introdução de novas práticas culturais traz uma nova forma de olhar, de fazer a leitura dos fenômenos da natureza, como no caso das enchentes quando o "rio está nos paus" ou "nas tampas", expressões muito utilizadas para dizer que o nível das águas está muito elevado, de cheias intensas quando só se avistam as copas de algumas arvores. A introdução de novos costumes, não apenas alterou a paisagem como também fragilizou o modus vivendi dos pantaneiros. Desse modo, "nesta vasta região tradição e modernidade coexistem espacialmente entre interesses diversos e conflitantes" (VARGAS, 2006, p. 3). 
O Diário de Corumbá, datado de 30 de dezembro de 1977, em sua primeira página, estampa a seguinte reportagem: "A hora e a vez do Pantanal" o teor da mesma, era que o Governo Federal se preparava para entregar o plano de manejo para o Pantanal - do norte - considerando que a divisão do Estado de Mato Grosso e Mato Grosso do Sul, ocorreu em outubro de 1977. Entre as abrangências propostas pelo plano de manejo estava o aproveitamento turístico; a exploração e exportação de recursos naturais renováveis; a campanha educativa em defesa da flora e da fauna ameaçadas de extinção.

As contradições são evidentes e vêm acompanhadas do discurso de que o Pantanal é uma das regiões mais heterogêneas, onde ao lado de formidáveis campos de pastagens há áreas inundáveis e alagáveis e florestas com potencial madeireiro cobiçado pelas indústrias nacionais e estrangeiras, porém, o intuito do plano era frear tal cobiça. Todavia, para todos os efeitos, o referido plano mostraria o que deveria ficar como está e o que deveria e poderia ser explorado nos excepcionais ecossistemas tão peculiares da região. O discurso de cunho preservacionista estava visível, no entanto, as entrelinhas continham a real função do plano de manejo que consistia em fazer um levantamento do potencial econômico da região dos pantanais.

Nessa perspectiva, os mesmos discursos foram ao longo dos tempos adquirindo diferentes significações e valores de acordo com os interesses advindos de cada época, no cenário político e econômico. Se era necessário um movimento de reorientação e de conscientização no que se refere às questões politico-ambientais, coube, portanto, ao Estado promover e implantar ações visando à preservação dos pantanais bem como atribuir novas representações fomentando e fortalecendo laços ambientais que estivessem ligados à própria identidade de seus habitantes (VARGAS, 2006). Essa projeção se dá com um enfoque preservacionista que apresentou o Pantanal "como uma paisagem emblemática" e agregadora de valores 
simbólicos e sedutores. A mídia passa a apresentar o Pantanal como fortes apelos ambientais, sensibilizadores e promotores de uma nova identidade para o Estado. Tal fato relega não apenas aos pantanais, como também aos seus habitantes, certo "alijamento", portanto, conhecer e respeitar as características ambientais tão distintas e inerentes ao Pantanal e portadoras de uma valoração simbólica para os pantaneiros, deve ser fator indispensável no planejamento e implantação de uma agenda turística para essa região.

Nesse contexto, se por um lado, o Pantanal, é considerado a maior área em extensão de terras úmidas distribuídas em cerca de 140.000 km², abrangendo os Estados de Mato Grosso e Mato Grosso do Sul, além de áreas compartilhadas com a Bolívia e o Paraguai, além de ser Patrimônio da Humanidade e um Patrimônio Natural, também considerado uma Reserva da Biosfera pela UNESCO (2000), atua como uma área importantíssima para a manutenção do equilíbrio ambiental das águas da América do Sul, e ainda, de maior importância, considerado Patrimônio Nacional pela Constituição da República Federativa do Brasil (1988, art. 225), por outro lado, apresenta um mosaico de ecossistemas terrestres, aquáticos e semi- aquáticos interelacionados e constituídos por duas grandes formações naturais: a Bacia superior e a Bacia inferior ou Pantanal, sendo que cada uma delas possui características bióticas e abióticas definidas e próprias. Portanto, dois sistemas que interagem sendo dependentes na manutenção e funcionamento normal, proporcionando uma série de benefícios responsáveis pela qualidade de vida no local (EDIBAP, 1979).

A baixa declividade da planície contribui para o lento escoamento da precipitação das águas nas cabeceiras do rio Paraguai e demais tributários formadores. Estima-se um período de aproximadamente quatro a cinco meses para que essas águas atravessem toda a planície. Seu clima quente e úmido no verão e frio e seco no inverno são fatores reguladores para a renovação dos ecossistemas que compõem o bioma pantaneiro. Essa 
composição é resultante por sua vez de outros ecossistemas que compõem outros grandes biomas como Amazônia, Cerrado, Mata Atlântica e o Chaco cujas características são áreas sem inundações, áreas inundáveis, ambientes aquáticos com água salobra ou água doce, vazantes, os cursos de águas intermitentes conhecidos como corixos, as baías e os rios. Solos arenosos, em sua maior parte sustentam pastagens naturais/nativas muito apreciadas pelos rebanhos bovinos e pela fauna nativa.

As enchentes que ocorrem no Pantanal, não podem ser comparadas às enchentes que acontecem em outras regiões. O que chamamos de Pantanal é um conjunto de ecossistemas, são vários pantanais marcados por características específicas locais. Citamos como exemplo os pantanais do rio Negro e do rio Aquidauana que juntam suas águas nos períodos das cheias. A planície tem seus ciclos climáticos marcados pelas enchentes e sua antítese, as secas. As inundações podem ser de curta duração, mas são responsáveis pela manutenção do equilíbrio ecológico dos pantanais. Com as águas, ocorre a renovação das pastagens, dos rios, das lagoas e corixos que compõem o sistema hídrico da planície que são reabastecidos, ou seja, a abundância das águas significa a abundância da vida, animal e vegetal dentro de ecossistemas aquáticos e terrestres com características específicas e diferenciadas. Para Vargas (2006),

A abundância de água implica na abundância de vida animal e vegetal. Cursos d'água e lagoas servem de habitat para numerosas espécies de vegetação aquática, conhecidas regionalmente por aguapés e camalotes, podendo constituir verdadeiras "ilhas" na imensidão hídrica. Por outro lado, a ictiofauna e a avifauna pantaneiras também são revigoradas pelo fenômeno das enchentes (VARGAS, 2006, p. 4).

Nesse contexto, um mosaico integrado de paisagens e de espaços geoecológicos podem ser visualizados na medida em que a água retoma o seu curso. Obviamente as cheias nos pantanais causam transtornos e exigem deslocamentos, como foi o caso de Porto Murtinho nas enchentes 
de 1979 e 1982, quando toda a população foi abrigada num acampamento provisório que foi chamado pelos moradores de "cidade de lona", mas, ao mesmo tempo, as águas trazem com elas a dualidade da vida e da morte, um enigma que o morador dos pantanais tenta em vão desvendar. A imagem das águas aguça a imaginação, o estranho serpentear das águas, alterando a paisagem, exigindo adaptações e renúncias.

Com os períodos de seca mais intensa e com o aumento da temperatura, como previsto pelas mudanças climáticas em nível global, fatores esses externos ao Pantanal, que, no entanto, podem contribuir para mudanças nos ciclos das águas que chegam à planície com períodos cada vez mais intensos de estiagem, ora diminuindo o volume das águas ou mesmo aumentando sua área de espraiamento. Esse fator agravado em termos de frequência pode levar ao comprometimento do bioma, posto que o Pantanal seja um conjunto de ecossistemas interligados. Entre os anos de 1963-1973, houve um período de estiagem, uma seca mais prolongada que comprometeu o sistema hídrico pantaneiro e a pecuária, principal atividade econômica do Pantanal. Por ter sido um fenômeno natural e numa época de pouca intervenção na bacia e nos rios formadores do Pantanal, as consequências ecológicas foram revertidas, por meio da resiliência, ou capacidade de recuperação, característica de ambientes saudáveis. Contudo, à medida que as ameaças à sua conservação vão aumentando, com seus processos ecológicos alterados pelos impactos ambientais, sua capacidade de recuperação fica cada vez mais comprometida.

Em 1974, ocorre uma grande enchente no Pantanal, após este período prolongado de estiagem, considerada como "uma das maiores calamidades sócio-econômicas que já se presenciou na história do Pantanal" (PROENÇA, 1997, p. 153). Muitos investimentos se diluíram tal quais as águas. Fazendeiros como "num abrir e fechar de olhos viram suas fazendas submersas" (op. cit.). Proença (1997) faz uma observação que mostra como 
se processa a relação do homem com o meio ambiente, a percepção das mudanças e de que havia alguns limites impostos para a ação humana no Pantanal. Para o autor, "a natureza mais uma vez fazia das suas, vencia o homem, transbordava excessivamente, e não sei se pregava uma lição." (op. cit.). Toda enchente é vista como um processo de recuperação do Pantanal. Um recurso regulador, operando na limpeza natural dos campos, reabastecendo de água as baías e corixos, recuperando os ecossistemas. Nessa enchente, com a perda considerável do rebanho bovino, muitas propriedades foram vendidas ou abandonadas.

O crescente efeito da degradação ambiental vem mudando a paisagem, tal qual fazem as águas que mudam e alteram a geografia local, gestando paisagens imaginárias. Citamos como exemplo dessa transformação, a Transpantaneira. Rodovia, em cujo projeto de construção faltou estudos adequados quanto ao regime hidrológico da região, estudos de engenharia para averiguação dos melhores locais para construção de pontes. Inicialmente, eram construídos aterros e esperava-se a água para ver os pontos de arrombamento. Assim que estourasse, naquele ponto eram construídas as pontes. A construção da rodovia foi uma tentativa desastrosa. Engenheiros e máquinas não conseguiram avançar metade do percurso previsto das obras. As seguidas enchentes, na década de 1970 impediram a continuidade dos trabalhos. A Transpantaneira tornava-se intransitável nos períodos de chuvas, quando se formavam imensos lamaçais e a abertura de vãos nas pontes, impossibilitando o percurso.

Outros aterros e diques como os construídos por empresas particulares provocaram uma interferência sem igual, tanto reduzindo quanto aumentando significativamente o volume das águas das cheias. 0 desequilíbrio ambiental ao qual o Pantanal está exposto não somente opera mutações na paisagem com vem assoreando rios, córregos e baías. A mata ciliar é retirada em vários pontos e na medida em que se perde essa vegetação 
natural há o comprometimento da oferta de habitats e alimentação de muitas espécies e favorecimento de processos erosivos e assoreamentos.

O assoreamento do rio Taquari, um dos mais importantes rios da planície, alterou o curso das suas águas. Nas áreas de planalto, as margens com ausência da mata ciliar sofrem erosão constante que leva os solos predominantemente arenosos para o rio, diminuindo a vazão e a profundidade da água, provocando desvios de seu curso, mudando a distribuição de água e afetando muitas espécies de peixes e plantas aquáticas. Em meados dos anos 1990, o rio Taquari, com a intensificação por duas décadas da pecuária e das lavouras de soja no planalto, ficou comprometido e o assoreamento foi inevitável.

Considerado um dos principais rios da Bacia Alto Pantanal, o rio Taquari é leito de drenagem das águas da planície que deságua no rio Paraguai, passando por 16 municípios, sendo que a maior parte se localiza no Estado de Mato Grosso do Sul. Com sua nascente próxima a divisa com o Estado de Goiás, o Taquari segue por aproximadamente $850 \mathrm{~km}$ até desembocar no rio Paraguai, a jusante de Corumbá/MS. Nas décadas de 1940 e 1950, o trecho era navegável entre Coxim e Corumbá, pois tinha uma profundidade de 15 metros. Estudos desenvolvidos por pesquisadores da EMBRAPA demonstram que vários trechos, já na década de 1990, não chegavam a 1 metro de profundidade das águas. É como se a areia, no decorrer dos anos fosse lentamente afogando o rio.

A relação entre sociedade e natureza é discutida por Zarrilli (2000) ao analisar que, como parte integrante de um sistema economicamente globalizado, o homem interfere consideravelmente para o seu desenvolvimento e para a obtenção de recursos garantidores da sua sobrevivência. A exploração demasiada dos recursos naturais, bem como as tecnologias empregadas, desde os mais remotos tempos geraram impactos e interferências, consideradas em certos casos irreversíveis em diversas regiões. 
Portanto, o diferencial está no grau de intensidade de tais transformações atuando como determinantes na regeneração e recomposição do meio ambiente. Excedendo certos limites aceitáveis, tais interferências podem desorganizar os ciclos regeneradores e reprodutivos dos ecossistemas, a tal ponto de produzir colapsos ecológicos que exigem reajustes sociais. Para o autor, nesse sentido, é possível considerar essas interferências em seus graus de intensidade e seus reajustes sociais como meios para conhecer a situação e a evolução das regiões.

Aação da agropecuária com as técnicas de manejo e produção, que eram utilizadas no sul e sudeste do país, e as características geomorfológicas da bacia, de elevado potencial erosivo, contribuiu para que com a enxurrada, sedimentos fossem carregados para o leito do rio, por essa situação similar, passam muitos córregos e rios de toda a bacia. Com o leito comprometido, o baixo Taquari invade fazendas, desloca pessoas, ricos e pobres, refugiados ambientais, resultante da inundação permanente de cerca de $5.000 \mathrm{~km}^{2}$. $\mathrm{O}$ ciclo de cheias e secas anuais, o fenômeno que caracteriza um ambiente de planície de inundação como o Pantanal e favorece a elevada riqueza e densidade de espécies, refletida na produção pesqueira, por exemplo, não mais ocorre nessa área e nem mesmo a atividade agropecuária. Não há mais declividade na planície, um canal de drenagem. Em consequência do assoreamento a água extrapola seu curso natural.

Ab'Saber (1988), em seus estudos sobre as transformações e suas consequências para a planície pantaneira salienta que:

[...] os rios que chegam ao Pantanal, provenientes dos planaltos e escarpas circundantes, são os que mais trazem cargas poluidoras, devido ao seu transito por áreas agrícolas em expansão, que liberam caldas de agrotóxicos e fertilizantes, durante a estação das águas. São eles próprios que em áreas adjacentes aos pantanais, recebem produtos mercuriais, injetados nas suas águas a partir das zonas de garimpagem. Por ultimo, são eles também que acentuam uma poluição sedimentária, devido aos processos erosivos mais ou menos 
frequentes e setorialmente agressivos, em processo nos planaltos sedimentários regionais (AB'SABER, 1988, p. 28).

Uma planície sedimentar, naturalmente recebe carga de sedimentos. Entretanto, com o mau uso do solo e água no planalto, chegando a níveis entre 50 a $80 \%$ de desmatamento que compromete as nascentes e as matas ciliares da região de cabeceiras e trechos médios dos principais rios (MONITORAMENTO, 2009), cargas consideráveis de sedimentos são deslocadas para os leitos dos rios o que interfere grandemente na dinâmica das inundações que, por sua vez, comprometem de forma substancial os ecossistemas. O desmatamento nas áreas de planície, em cerca de 13\%, tem apresentado aumento expressivo devido à demanda por carvão vegetal para abastecimento de siderúrgicas em Mato Grosso do Sul e de outros estados do país como Minas Gerais e São Paulo. A pecuária é o uso antrópico mais representativo, respondendo por $11,1 \%$ da área antrópica na planície e por $43,5 \%$ da área antrópica do planalto. Os cultivos agrícolas representam apenas 0,3\% da área da planície e 9,9\% do planalto (MONITORAMENTO, 2009). A contaminação das águas por resíduos químicos e agrotóxicos utilizados para o desenvolvimento das atividades econômicas na região é fator responsável por alterações significativas da vida animal e vegetal nos pantanais interferindo nos seus ciclos reprodutivos, na saúde ambiental e na saúde humana.

Mesmo a pecuária tradicional, considerada no passado como tendo baixo impacto na planície, atualmente opera como elemento modificador da vegetação com o desmatamento e a introdução de pastagens alheias ao ambiente, substituindo as pastagens nativas. Trata-se de iniciativa dos fazendeiros na busca de maior produção, ampliando a área de pastagens mais eficientes em termos nutricionais, mas introduzindo espécies exóticas em locais onde as inundações são menos intensas como nas chamadas cordilheiras $^{11}$ que apresentam uma vegetação natural densa que tem a função 
de abrigar os próprios bovinos em picos de calor ou frio intenso, além do papel ecológico. A alteração do ambiente natural, adequado às necessidades que são impostas pelo modo de produção mais intensivo, resulta gradativamente em desequilíbrio da natureza.

O desmatamento vem crescendo a taxas elevadas na planície, e está presente, como vimos, de forma mais intensa no planalto. Muitos fazendeiros e pecuaristas, não tendo uma ligação direta com a cultura regional e com o Pantanal, buscam a uniformidade da paisagem. O respeito a diferentes unidades de paisagens e suas características próprias fica esquecido. A ideia de conservação, de preservação está atrelada a reservas particulares, vistas como reservas naturais ou em unidades de conservação governamentais. A cobertura vegetal original está comprometida. Na tentativa de reverter esses danos na sub-bacia do rio Taquari, a Secretaria do Meio Ambiente do Estado de Mato Grosso do Sul, em conjunto com fazendeiros, tem projeto ainda pequeno e em fase inicial de plantar mudas de espécies nativas nas áreas de proteção permanente (APPs), como matas ciliares e nascentes em São Gabriel do Oeste, na tentativa de conter a erosão.

De acordo com Calheiros et al. (2009) os prognósticos quanto a conservação do ciclo de cheias e secas, ou pulso de inundação, natural de cada rio (variação de nível, vazão e de periodicidade) do sistema BAP/ Pantanal são ainda mais preocupantes, uma vez que estão previstos um total de 116 empreendimentos hidrelétricos na bacia, 29 já implantados e mais 87 barragens em processo de construção, licenciamento, inventário ou estudo de viabilidade. Do total de projetos previstos para BAP, $75 \%$ estão na região norte, no Estado Mato Grosso, região responsável pelo abastecimento de $70 \%$ da água do sistema. Na principal sub-bacia, a do rio Cuiabá, responsável por $40 \%$ da água do sistema, todos os principais tributários já apresentam barramentos em seus principais afluentes (rios Manso/Casca, Itiquira, 
Correntes e São Lourenço), já sendo constatadas alterações do pulso de inundação no rio Cuiabá pela influência somente da barragem de Manso.

Grande parte (73\%) do total desses empreendimentos refere-se a Pequenas Centrais Hidrelétricas (PCHs), todavia muitas delas localizadas e/ou previstas para um mesmo rio, resultando num impacto conjunto significativo, semelhante ao efeito de um reservatório de grande porte. Além disso, as PCHs mesmo operando a "fio d'água", sem necessariamente formar reservatório, formam barreiras de altura elevada (10-40 m), resultando na retenção e, portanto, alteração da descarga de nutrientes e material em suspensão, importantes para o funcionamento ecológico da planície a jusante. Por outro lado, a presença de uma barreira física sabidamente impede a movimentação das espécies de peixes migratórios na fase de piracema, afetando a produção pesqueira em médio e longo prazo (FERNANDES et al., 2009). Desta forma, vislumbra-se um cenário preocupante relacionado ao elevado potencial do conjunto desses empreendimentos alterarem o regime de inundações sazonais e interanuais de forma significativa em toda a planície pantaneira.

A natureza do Pantanal pede respeito às singularidades do ambiente. Beleza e encantamento de um céu às avessas, no espelho das águas. Aprender a ler o Pantanal, a ver a natureza como portadora de aspectos que englobam um universo simbólico, representações construídas pelo homem temporalmente, são lições do cotidiano do morador dos pantanais. Suas experiências vividas são marcadas por elementos que envolvem um universo mítico, portanto:

Ao lado das ligações e das concepções inerentes ao universo sobrenatural ou mítico sobressaem indicações que demonstram o conhecimento sobre caminhos, clima, plantas e raízes medicinais, além das técnicas de trabalho em que o contato com a natureza é fator constante (LEITE, 2005, p. 184).

O morador da planície tem seu cotidiano marcado por histórias inacreditáveis de força e coragem, causos que envolvem onças e seres que 
moram no fundo das baías, que povoam a imaginação do pantaneiro. Para esse homem familiarizado com o meio em que vive, fazer essa leitura é como decifrar mensagens emitidas pela natureza, tão necessário quanto trivial, posto que:

A entrada na mata, a travessia do rio, o pouso em local ermo são momentos de aplicação e adaptação de conhecimentos e crenças que foram transmitidas desde longos tempos. São ainda instantes de tensão entre o saber tradicional e a natureza, são momentos de memória e de história, de interpretação e significação daquilo que se sabe por experiência própria ou de outrem e podem proporcionar novos saberes (LEITE, 2005, p. 184).

Embora, para aquele que chega alheio ao ambiente, àquele que "vem de fora", não parece tão simples assim. A falta de familiaridade dá respostas imediatas, será visto apenas aquilo que os olhos estão aptos e acostumados a ver. É preciso primeiro entender que se trata de uma área onde é possível verificar uma grande diversidade natural (MORETTI, 1996, p. 18) e, portanto, cultural.

Como observado, com a enchente de 1974 a região passou por um processo de estagnação econômica no setor agropecuário. Houve uma perda considerável do rebanho bovino. Assim, a expectativa de alavancar a economia fez com que a atividade turística ganhasse corpo como novo segmento econômico no Pantanal. Contemplar a natureza e desfrutar da pesca foram elementos determinantes para a atividade turística. Uma teia de serviços é articulada e nela incluíram-se empresas de turismo, hotéis, restaurantes, aluguel de barcos, oficinas de reparo para pequenas embarcações, trabalhadores autônomos como catadores de iscas, piloteiros, guias e pescadores. $O$ turismo trouxe a preocupação de adequar a natureza às necessidades do visitante, para tanto, era necessária a eliminação dos aspectos vistos como negativos.

Visto pelo ângulo do desenvolvimento, o turismo é um incentivo que deveria ter um efeito multiplicador, beneficiando as populações locais. Hist. R., Goiânia, v. 19, n. 2, 2014 
Valorizando o homem e o lugar, dinamizando o local, com atenção voltada para o patrimônio natural, histórico e cultural. Ter como objetivos a socialização, oportunidades de promoção e desenvolvimento, processo de câmbio social, de mudanças e orientações. Estímulos à cooperação, criatividade, utilização de recursos naturais visando à preservação. Apoio das políticas públicas como fomento para o turismo histórico e cultural, considerando as experiências e os costumes, o estilo de vida das comunidades, integrando as pessoas, operando dentro de condições naturais. No entanto, buscou-se uma adequação, e em muitos casos, alijando o homem de seu espaço.

O número de turistas, registrados na década de 1990 , era de apenas um brasileiro para cada dez estrangeiros que visitam os pantanais. Turistas esses recebidos nas mais de 500 hotéis e pequenas pousadas da região. Pesquisa realizada em 1997, pela Revista Veja de junho de 1999 apontava o Pantanal e Bonito como o segundo local que os brasileiros desejavam conhecer. E, para receber esse número de turistas o Pantanal passou por transformações profundas, onde fazendas passam a ser pousadas e recantos ecológicos, os peões acostumados com a lida do gado passam a ser guias turísticos, tendo as comitivas de transporte de bois como atrativos.

As transformações às quais a planície foi exposta em todos esses anos, especialmente nas décadas de 1970-1990, intensificaram as pressões sobre a natureza e suscitaram adequações na relação do homem com a natureza que passa a ser vista como um recurso a ser explorado. Como resultado, o tempo e o ritmo de trabalho se alteram, ou seja, o tempo de trabalho não se adapta mais ao meio ambiente pantaneiro. O respeito ao tempo e à natureza, característico da população pantaneira e reconhecido por outras culturas como lento e com períodos de ociosidade é posto a prova. As atividades desenvolvidas localmente até então, de maneira geral estavam integradas ao ritmo da natureza e as necessidades do pantaneiro eram supridas com poucas alterações no seu ambiente natural. 
Se considerarmos, de acordo com Martinez (2006), que fazer História é buscar as sociedades e entendê-las em seu meio, desenvolver pesquisas e atividades educativas que possibilitem o entendimento da problemática ambiental em todos os seus aspectos, sejam históricos, ecológicos, sociais, econômicos e culturais, consequentemente é possível produzir diálogos viabilizando a construção de novos conhecimentos que não sejam apenas pautados em catástrofes ambientais, mas que contemplem nas suas análises as formações sociais, em todos os seus aspectos (MARTINEZ, 2006, p. 19). Tais ponderações nos levam a não dissociação de vínculos e relações do homem com o meio ambiente, às significações, às representações e simbologias que permeiam as experiências do vivido em determinados espaços, sua relação com o universo natural.

Nos estudos desenvolvidos no campo da História Ambiental, não se propõe a fragmentação, ou seja, não se pode estudar a natureza sem a análise da sociedade em todos os seus aspectos. Entende-se que não é possível um entendimento se houver uma fragmentação. Quando a proposta é estudar a relação do homem com a natureza nos pantanais, aspectos como as transformações ambientais vinculados ao desenvolvimento econômico da região que compreende o Pantanal, não podem ser desconsiderados. Abordagens históricas da constituição do espaço e das territorialidades associados às experiências vividas, possibilitam um calidoscópio na construção de uma historiografia mais abrangente, envolvendo a dinâmica e os mecanismos sociais, resultando em novas questões e debates pertinentes à temática.

As relações entre homem e natureza nos pantanais, aqui ressaltadas, são complexas, e envolvem experiências vividas e estratégias que permitam a continuidade e permanência no local. Nas pesquisas desenvolvidas, buscamos através de entrevistas, da oralidade os referenciais do passado, os aspectos de uma cultura gestada e transmitida por gerações, 
a maneira de ser e as interpretações de um sistema cultural abrangente de imagens e códigos, em que as enchentes atuam como um elemento portador de ambiguidades.

Os homens constroem seu mundo pela sua percepção e pela cultura, bem como também através de um conjunto de elementos que estão presentes nas subjetividades. A construção se dá a partir das experiências que envolvem os mecanismos da percepção. São as experiências os fatores que contribuem para a também construção de sua visão de mundo. A presença do homem nos pantanais resultou na sua interação com a natureza e tem importância significativa na construção de uma identidade regional e cultural. A cultura pantaneira não poderia sobreviver sem o Pantanal.

\section{Notas}

(Endnotes)

1 CAMPOS, C. Pantanal Mato-grossense: O semantismo das águas profundas. 2004, p.42

2 Estudos produzidos por pesquisadores da EMBRAPA Pantanal mostram as Sub-regiões definidas para a área físiográfica do Pantanal: Cáceres; Poconé; Barão de Melgaço; Paraguai; Paiaguás; Nhecolândia; Abobral; Aquidauana; Miranda; Nabileque; Porto Murtinho. Sendo essa área fisiográfica composta por 15 municípios, sendo 6 no Estado do Mato Grosso ocupando 34,27\% da área do Pantanal e 9 no Estado do Mato Grosso do Sul, ocupando $65,73 \%$ da área do Pantanal. Sendo Corumbá (44,31\%), Poconé (10,01\%), Cáceres $(9,44 \%)$ e Aquidauana $(9,31 \%)$, os municípios que mais contribuem para a formação da área do Pantanal.

3 Nesta perspectiva de análise contamos com estudos produzidos por: BORGES, F.T.M. Do extrativismo á pecuária: algumas observações sobre a história econômica do Mato Grosso (1870-1930). 2a ed. São Paulo. Scortecci, 2001; LENHARO, A. Colonização e trabalho no Brasil. Campinas: Ed. Da UNICAMP, 1985; LENHARO, A. A terra para quem nela trabalha. (A especulação com a terra no oeste brasileiro nos anos 50). Revista Brasileira de História, São Paulo: v.6, n. 12, p. 47-64, mar/ago- 1986.

4 A implantação do PRODEPAN, contava com a participação dos seguintes órgãos: Ministério dos Transportes; Rodovias e rede hidrográfica; DNOS com programa se saneamento ambiental, regularização das águas do rio Paraguai e seus afluentes, com vistas ao controle das enchentes, aproveitamento hidroviário, saneamento básico, abertura de canais, perfuração de poços; Ministério das Minas e Energia: ELETROBRAS com Programa de expansão da 
oferta de energia. Ministério da Agricultura: CONDEPE - EMBRAPA; e SUDECO com o programa de industrialização.

5 A perfuração de 74 poços sendo 31 construídos em campos experimentais e os demais foram suspensos - segundo relatório foram construídos 50 poços - uma quantidade não exata e motivo de zombaria para os fazendeiros, são conhecidos como "poços da viúva" (a "mãe pátria"). Muitas obras foram abandonadas sem concluídas, outras constam em mapas, mas não há evidencias da sua realização, como por exemplo, o dique-estrada foi adiado e recursos foram cortados - área abandonada tomada por posseiros; Polder experimental de Corumbá -Ladário - obra foi abandonada. Toda a Estrutura físico-econômica foi pensada e planejada baseada nos estudos de cheias/secas que apontavam 15 anos de secas que foram interrompidas pelas cheias de 1974 e a não realização da grande maioria das obras de infraestrutura previstas, recursos contraídos da poupança externa alimentaram a divida externa brasileira.

6 O "descuido técnico": para as rodovias a estrutura pensada não estava preparada para adaptações considerando os períodos das cheias; a implantação de rodovia prejudicou o escoamento natural das águas provocando inundações excepcionais em área que não eram atingidas pelas enchentes.

7 Trabalho realizado por uma equipe interdisciplinar da UFMT apresenta o estudo da relação entre as populações ribeirinhas, pequenos pescadores e criadores de gado e as flutuações hídricas do Pantanal. Relação essa que contempla uma bagagem considerável de conhecimento dessas populações e o seu modo tradicional de vida na região. Ler a respeito na obra de SILVA, C J da. E J. A. F. Silva. No ritmo das águas do Pantanal. NUPAUB/ USP. São Paulo: USP, 1995. Sobre as relações do vaqueiro com a sociedade e com o mundo natural e a forma como as representações são atualizadas nas experiências cotidianas ver: BANDUCCI JUNIOR, Álvaro. A natureza do pantaneiro: relações sociais e representações de mundo no "Pantanal da Nhecolândia". Campo Grande, MS: Ed. UFMS, 2007.

8 As cordilheiras são cordões de matas presentes em pequenas elevações localizadas na planície pantaneira, que não são atingidas pelas águas nos períodos de inundações. Com uma vegetação tipo cerradão é o refugio dos animais nos períodos das cheias.

\section{REFERÊNCIAS}

AB'SABER, A. N. O Pantanal Mato-Grossense e a teoria dos refúgios. Revista Brasileira de Geografia. Rio de Janeiro: IBGE n. 50 p. 9-57, 1988.

AB'SABER, A. N. Brasil: Paisagens de Exceção. O litoral e o Pantanal Matogrossense: patrimônios básicos. Cotia, SP: Ateliê Editorial, 2006.

BAÉZ, R. Corumbá: reminiscências e impressões. Corumbá, 1975 
BANDUCCI JUNIOR, A. A natureza do Pantaneiro: relações sociais e representação de mundo no "Pantanal da Nhecolândia". Campo Grande, MS: Ed. UFMS, 2007.

BRASIL. Constituição da República Federativa do Brasil de 1988.

BRASIL. 2001. Programa de Desenvolvimento Sustentável do Pantanal Programa Pantanal. Ministério do Meio Ambiente. Secretaria de Qualidade Ambiental nos Assentamentos Humanos. Sumário Executivo. 32 p. Disponível em: $\quad$ http://yyy.rsmas.miami.edu/IAl/Inst2001/miniprojects/pantanal/ backgr/panprog/PP-Port.pdf>. Acesso em: 05 abr. 2011.

BRASIL. Ministério do Interior. Estudos de Desenvolvimento Integrado da Bacia do Alto Paraguai (EDIBAP): relatório 1ạ fase. Descrição física e recursos naturais. Brasília, 1979. t. 2.

BRASIL. Ministério do Interior. EDIBAP. Relatório da 1a fase - TOMO I. Resumo do Diagnóstico e Estratégias e Desenvolvimento. Ministério do Interior. Superintendência do Desenvolvimento da Região Centro-Oeste - SUDECO. Convenio: Governo Brasileiro - UNDP-OEA. Brasília: novembro/1979.

BRASIL. Ministério do Meio Ambiente dos Recursos Hídricos e da Amazônia Legal (Brasília, DF). Plano de Conservação da Bacia do Alto Paraguai (Pantanal) - PCBAP: Análise integrada e prognóstica da Bacia do Alto Paraguai. Brasília, 369 p. 1997.

CALHEIROS, D. F.; ARNDT, E.; RODRIGUEZ ORTEGA, E.; SILVA, M. C. A. Influência de usinas hidrelétricas no funcionamento hidro-ecológico do Pantanal Matogrossense - Recomendações. Corumbá: Embrapa Pantanal, 2009. Série Documentos (DOC 102). 21 p. Disponível em: <http://www.cpap.embrapa. br/publicacoes/online/DOC102.pdf>. Acesso em: 11 fev. 2011.

CAMPOS, Cristina. Pantanal Mato-grossense: o semantismo das águas profundas. Cuiabá: Entrelinhas, 2004.

CAMPOS FILHO, L. V. Tradição e ruptura; cultura e ambiente pantaneiros. Cuiabá: Entrelinhas, 2002. 184 p.

CORRÊA, L. Salsa. História e fronteira: o Sul de Mato Grosso (1870-1920). Campo Grande: UCDB, 1990. 243 p. 
CORREA FILHO, Virgilio. Pantanais Matogrossenses (Devassamento e ocupação). Publicação n. 3, Série A. Ed. Instituto Brasileiro de Geografia e Estatística, Rio de Janeiro: 1946.

EMBRAPA PANTANAL. Impactos ambientais e sócio-econômicos no Pantanal. Corumbá, 1997a.

FERNANDES, F. A. G. Entre histórias e tererés: o ouvir da literatura pantaneira. São Paulo: Editora UNESP, 2002.

FERNANDES, R.; AGOSTINHO, A. A.; FERREIRA, E. A.; PAVANELLI, C. S.; SUZUKI, H. I.; LIMA, D. P.; GOMES, L. C. 2009. Effects of the hydrological regime on the ichthyofauna of riverine environments of the Upper Paraná River Floodplain. Brazilian Journal of Biology, 69 (2 suppl.), 669-680.

HAMILTON, S. K.; SIPPEL, S. J.; MELACK, J. M. Inundation patterns in the Pantanal wetland of South America determined from passive microwave remote sensing. Archiv fur Hydrobiologie, v.137, p.1-23, 1996.

HORTA Duarte R.; OSTOS N. S. C. Entre Ipês e Eucaliptos. Nómadas, n. 22 abril 2005. Universidad Central - Colômbia.

KMITTA, I. R. Experiências vividas, naturezas construídas: Enchentes no Pantanal (Porto Murtinho 1970-1990). 2010. Dissertação (Mestrado em História) - Faculdade de Ciências Humanas, Universidade Federal da Grande Dourados (UFGD), Dourados, MS, 1997.

LEFF, ENRIQUE. Vetas y Vertientes de la Historia Ambiental Latinoamericana: Una nota metodológica y epistemológica. Rich Seams and Perspectives in Latin American Environmental History An epistemological and metodological view. VARIA HISTÓRIA, volume 21, no 33 Janeiro, 2005. p. 17-31

LEITE, E. F. Marchas na história: comitivas e peões-boiadeiros no Pantanal. Brasília: Ministério da Integração Nacional; Campo Grande, MS: Ed. UFMS, 2003.

LEITE, E. F. Anotações sobre cultura e natureza nos pantanais. Diálogos, DHI/ PPH/UEM, v. 9, n. 1, p. 167-188, 2005.

MARTINEZ, Paulo Henrique. História Ambiental no Brasil: pesquisa e ensino. Coleção questões da nossa época. São Paulo: Ed. Cortez, 2006. 
MONITORAMENTO. 2009. Monitoramento das alterações da cobertura vegetal e uso do solo na Bacia do Alto Paraguai - Porção Brasileira, Período de Análise: 2002 a 2008. Brasília: Cl - Conservação Internacional, ECOA - Ecologia e Ação, Fundação AVINA, Instituto SOS Pantanal, WWF- Brasil. Relatório Técnico. Disponível em:

<http://www.wwf.org.br/informacoes/bliblioteca/?25181/Monitoramentodas-alteracoes-da-cobertura-vegetal-e-uso-do-solo-na-Bacia-do-AltoParaguai>. Acesso em: 22 abr. 2010.

MORETTI, E. C. Problemática Ambiental no urbano: análise da ocupação do espaço e sua relação com a natureza no Pantanal (Corumbá). 1996. Dissertação (Mestrado em Geografia) - Faculdade de Ciências e Tecnologia. Universidade Estadual Paulista "Júlio de Mesquita Filho" - Presidente Prudente, SP.

NOGUEIRA, A. X. Pantanal: Homem e cultura. Campo Grande: Ed. UFMS, 2002. 156 p.

PÁDUA, José Augusto. As bases teóricas da História Ambiental. Estudos Avançados 24 (68), 2010. p. 81-101

PRODEPAN. Pantanal, nova fronteira econômica. I Encontro do Programa de Desenvolvimento do Pantanal. Conferências, Proposições e Subsídios. Governo do Estado de Mato Grosso. Secretaria da Agricultura. Corumbá, 1974.

PROENÇA, Augusto César. Pantanal: gente, tradição e história. 3. ed. Campo Grande, MS: Ed. UFMS, 1992.

Revista Veja, edição 1600, ano 32 n. 22, de 02 de junho/1999.

SILVA, E. N da. A modernização da agricultura: uma aproximação histórica do caso brasileiro e mexicano (1970-1980). Revista Territórios e Fronteiras. V. 3, n. 1 Jan./jun. 2010. ICHS/UFMT.

SILVA, J. dos S. V. da; ABDON, M. de M. Delimitação do Pantanal brasileiro e suas sub-regiões. Pesquisa Agropecuária Brasileira, Brasília, v. 33, p. 17031711, 1998.

TUAN, Yi-Fu. Topofilia. Um estudo da percepção, atitudes e valores do meio ambiente. São Paulo: DIFEL, 1980. 
$\overline{\text { VARGAS, I. A. O desenvolvimento territorial rural do Pantanal Mato-grossense }}$ no contexto da sensibilização ambiental. Anais do VII Congresso Latino Americano de Soc. Rural. Quito, Nov./2006. p. 1-18.

WILCOX, R.W. La ley del menor esfuerzo: El médio ambiente y la industria da ganado em Mato Grosso, Brasil 1870-1980, In: ARRUDA, Gilmar, et.al, eds. (Natureza: Apropriações e Representações na América (Londrina-Brasil: Universidade Estadual de Londrina, 2001). 2001

ZARRILII, A. Transformacion ecológica y precariedad econômica em uma economia marginal. El Grann Chaco Argentino, 1980-1950. Revista THEOMAI, n. 1 (primeiro semestre, 2000). 